\title{
ANALYSIS OF SUPPLIER'S PERFORMANCE THROUGH FPIR/FNIR AND MEMBERSHIP DEGREE TRANSFORMATION
}

\author{
S.Hemalatha ${ }^{1}$ K. Ram Babu ${ }^{2}$ K.Narayana Rao ${ }^{3}$ K.Venkatasubbaiah ${ }^{4}$ \\ ${ }^{1}$ Department of Mechanical Engg, Lendi Institute of Engineering and \\ Technology, Vizianagaram- 535005 \\ ${ }^{2}$ Department of Mechanical Engg, Andhra University, Visakhapatnam-530 007 \\ ${ }^{3}$ Government Model Residential Polytechnic, Paderu-531024 \\ ${ }^{4}$ Department of Mechanical Engg, Andhra University, Visakhapatnam-530 007
}

\begin{abstract}
In today's highly competitive business environment, evaluation of suppliers is the prime function of the purchasing department of the organization. It is due to the fact that high percentage of the material cost for manufacturing of a product is involved. Identification of decision criteria and methods for supplier evaluation are appearing to be the important research area in the literature. In this paper, hybrid methodology of Fuzzy positive Ideal rating /Fuzzy Negative Ideal rating and Membership Degree Transformation- $M(1,2,3)$ is proposed for evaluation of supplier's performance. A wide literature review is made and six selection criteria namely: Cost, Quality, Service, Business performance, Technical Capability and Delivery performance are considered for evaluation. A detailed application of the proposed methodology is illustrated. The proposed methodology is useful not only to judge the overall performance of the supplier but also to know which criteria/sub-criteria need to be improved.
\end{abstract}

\section{KEYWORDS}

Membership Degree transformation; Fuzzy positive Ideal Rating; Fuzzy Negative Ideal Rating; Supplier performance;

\section{INTRODUCTION}

The traditional business functions need to be coordinated to achieve customer satisfaction, value, profitability, and competitive advantage for individual companies and the entire supply chain. One of the functions that have been singled out as important in the coordination processes of the individual firms and supply chain is purchasing.

Cheraghi et al (2002) presented the critical success factors (CSFs) for supplier selection reported in the literature emanating from the seminal work of Dickson (1966) and provide an update based on reviewing more than 110 research papers. The authors indicated significant change in the relative importance of various critical success factors in the research reported during 1966-1990 versus 1990-2001. Supplier selection and their performance evaluation is one of the important 
drivers of supply chain performance. Uses of suitable criteria with appropriate methodologies are necessary for performance evaluation of a supplier. In the literature, it is observed that supplier selection and evaluation methods were based on quoted price, quality, business relations, lead time etc., constitute a multi-criteria or multi-objective decision making problem. The overall objective of the supplier selection process is to identify, evaluate, contract with the suppliers and optimum quota allocation to the suppliers. Boer et al (2001) made a review on decision methods on supplier selection based on academic literature. Byun (2001) presented Analytical Hierarch Process (AHP) approach for vendor selection and identified supplier reliability, product quality and supplier experiences are the critical factors for effective supplier selection in Korean automobiles. Muralidharan et al (2002) suggested guidelines for comparing supplier attributes using a five-point rating scale and developed aggregation technique for combining group member's preferences into one consensus for supplier rating. In the supplier selection process, organizations judge the supplier's ability to meet the requirements of the organization to survive in the intensely competitive global economy. Dulmin and Mininno (2003) used multi-criteria decision analysis method in supplier selection problem using PROMETHEE and GAIA methodology. Rajkumar and Ray (2004) identified attributes and factors relevant for performance evaluation of suppliers through fuzzy inference system of the MATLAB fuzzy logic tool box. Venkatasubbaiah and Narayana Rao (2004) considered thirty three sub-criteria under six main criteria reported in the literature in four decision hierarchy levels for supplier selection using AHP. Very often, experts opinion is the prominent characteristic of multi-criteria decision making problems and this impreciseness of human's judgments can be handled through the fuzzy sets theory developed by Zadeh (1965). Fuzzy set theory effectively incorporates imprecision and subjectivity into the model formulation and solution process. Chen et al (2006) adopted TOPSIS concept in fuzzy environment to incorporate imprecision and subjectivity into the model formulation and solution process to determine the ranking order of the suppliers. The author considered the factors such as quality, price, and flexibility and delivery performance. Lee et al (2007) adopted Fuzzy Analytic Hierarchy Process (FAHP) to analyze the importance of multiple factors by incorporating the experts' opinions to select Thin Film Transistor Liquid Crystal Display (TFT-LCD) suppliers. Narayana Rao et al (2007) illustrated fuzzy outranking technique for selection of supplier using minimum and gamma operators for aggregating the concordance and discordance indices of the alternative suppliers to arrive the ranking of suppliers with credibility values. Shouhua Yuan et al (2008) proposed DEA, AHP and fuzzy set theory to evaluate the overall performance of suppliers of a manufacturing company. Enyinda et al (2010) adopted analytic hierarchy process (AHP) model and implemented using Expert Choice Software for a supplier selection problem in a generic pharmaceutical organization. Elanchezhian et al (2010) adopted analytical network process (ANP) and TOPSIS method for select the best vendor. Jitendra Kumar and Nirjhar Roy (2010), adopted a hybrid model using analytic hierarchy process (AHP) and neural networks (NNs) theory to assess vendor performance. Yucel and Guneri (2011) assessed the supplier selection factors through fuzzy positive ideal rating and negative ideal rating to handle ambiguity and fuzziness in supplier selection problem and developed a new weighted additive fuzzy programming approach. Yang and Jiang (2012) proposed AHM (Analytic Hierarchy Method) and $\mathrm{M}(1,2,3)$ methodology to evaluate the supply chains' overall performance. Durga Prasad et al (2012) proposed and illustrated the methodology for evaluating the efficiency and performance of the suppliers using Data Envelopment Analysis (DEA) technique. Amindoust (2012) proposed and illustrated ranking methodology in fuzzy environment with sustainable supplier selection criteria/sub-criteria. Abbasi et al (2013) proposed a framework and applied QFD/ANP to rank the relative importance of the key attributes in selection of suppliers. Galankashi et al (2013) presented supplier Selection for Electrical Manufacturing Companies Based on Different Supply Chain Strategies using AHP. Eshtehardian et al (2013), 
presented a decision support system to the supplier selection in the construction and civil engineering companies using AHP and ANP simultaneously. Om pal et al (2013) presented review on supplier selection criteria and methods basing on research reported in the supply chain management area. Deshmukh and Vasudevan (2014) explored criteria that are important for green supplier selection, as evident in literature and gathered from discussions with experts. Ergün and Atalay (2014) proposed FAHP and FTOPSIS for evaluation of suppliers of an electronic company.

From the review of literature, it is observed that there is limited research in group decision approach for prioritizing the supplier selection criteria in fuzzy environment. Further, classification of a supplier belongs to a particular class basing on the data mining technology is also limited. In lieu of this, a hybrid methodology is proposed for evaluation of supplier's performance and illustrated by considering the supplier of a pharmaceutical company. In the methodology, Fuzzy positive Ideal Rating and Fuzzy Negative Ideal rating approach is adopted to find out the importance weights of criteria/sub-criteria. Then, Membership transformation method $-\mathrm{M}(1,2,3)$ is adopted to find out the grade of overall performance of a supplier. Proposed methodology is explained in section two. Numerical Illustration is presented in section three. Results and discussion is made in section four. Finally, the conclusions are summarized with future scope in section five.

\section{METHODOLOGY}

\section{Step 1: Establish Evaluation Index System of Supplier Performance}

An Organization has to identify criteria for supplier selection to evaluate whether the supplier fits its competitive strategy and supply chain strategy. The total performance of the supplier depends on the capabilities in each criteria/sub criteria and the relative importance given to them.

\section{Step 2: Determine importance weights of the criteria/sub criteria}

Fuzzy Positive Ideal Rating (FPIR) and Fuzzy Negative Ideal Rating (FNIR) are used to compute the weights of the criteria/sub criteria (Yucel and Guneri, 2011).

\section{Step 3: Membership Transformation through "Effective, Comparison and Composition"}

Membership transformation method - M(1,2,3) proposed by Hua and Ruan (2009) as discussed in the following steps is adopted to determine the evaluation matrix of the alternative.

\section{Step 3.1: Determine Evaluation Membership $\mu_{j k}(Q)$}

Percentage of satisfaction among the domain experts under each class is considered as evaluation matrix of each criterion.

$\mu_{j k}(Q)=$ membership of $\mathrm{j}^{\text {th }}$ sub-criteria of the criteria group ' $\mathrm{Q}$ ' belonging to the $\mathrm{k}^{\text {th }}$ fuzzy membership class. 


\section{Step 3.2: Determine Distinguishable Weights $\left(\alpha_{j}(Q)\right)$}

Distinguishable weight represents the normalized and quantized value obtained from the following relation.

$$
\alpha_{j}(Q)=v_{j}(Q) / \sum_{j=1}^{m} v_{j}(Q) \quad(j=1 . . m)
$$

Where

$v_{j}(Q)=1-(1 / \log (p)) * H_{j}(Q)$

$H_{j}(Q)=-\sum_{k=1}^{p} \mu_{j k}(Q) * \log \mu_{j k}(Q)$

$v_{j}(Q)=$ weight of the jth sub criteria of the evaluation criteria object ' $Q$ ' obtained from uncertainty in the payoff information of the sub criteria

$H_{j}(Q)=$ Measure of uncertainty in the payoff information of the jth sub criteria of the evaluation criteria object ' $Q$ '

Step 3.3: Determine Comparable sum Vector $M_{k}(Q)$

Comparable value of the sub criteria under the given criteria is determined from the following relation

$M_{k}(Q)=\sum_{j=1}^{m} \beta_{j}(Q) * \alpha_{j}(Q) * \mu_{j k}(Q)$

$\beta_{j}(Q)=$ Importance Weight Vector of sub-criteria

Step 3.4: Determine Membership Vector $\mu_{k}(Q)$

Membership vector of the object ' $Q$ ' belonging to class ' $\mathrm{k}$ ' is determined from the following relation.

$\mu_{k}(Q)=M_{k}(Q) / \sum_{k=1}^{p} M_{k}(Q)$

Step 3.5: Determine Evaluation Matrix of the alternative U(S)

Membership matrix of all the criteria of the object ' $Q$ ' is determined and evaluation matrix is formed as shown below. 
$\mathrm{U}(\mathrm{S})=\left(\begin{array}{l}\mu(C 1) \\ \mu(C 2) \\ \mu(C 3) \\ \mu(C 4) \\ . . \\ . .\end{array}\right)$

\section{Step 4: Determine Final membership Vector $\mu(S)$}

Once the evaluation matrix of the goal and the weights of the each criterion are known the procedure is repeated from the step 3.1 to 3.5 is repeated to obtain the final membership vector of the goal.

\section{Step 5: Determine the grade of overall Performance $\left(\mathrm{K}_{\mathrm{O}}\right)$}

Overall performance of the alternative is determined by applying confidence recognition rule (Confidence degree: $\lambda_{>0.7)}$

$\mathrm{K}_{\mathrm{O}}=\min \left\{\mathrm{kl} \sum_{k=1}^{k} \mu_{k}(S) \geq \lambda\right\}$

\section{NUMERICAL ILLUSTRATION}

In this paper, supplier performance evaluation using proposed methodology is illustrated with a numerical example. Supplier's performance metrics taken from the literature (Venkatasubbaiah et al., 2004; Lee et al., 2007; Narayana rao et al., 2007) are considered for performance evaluation of supplier. The evaluation hierarchy is organized into three layers namely, Goal, Criterion layer and sub-criterion layer as shown in fig 1.
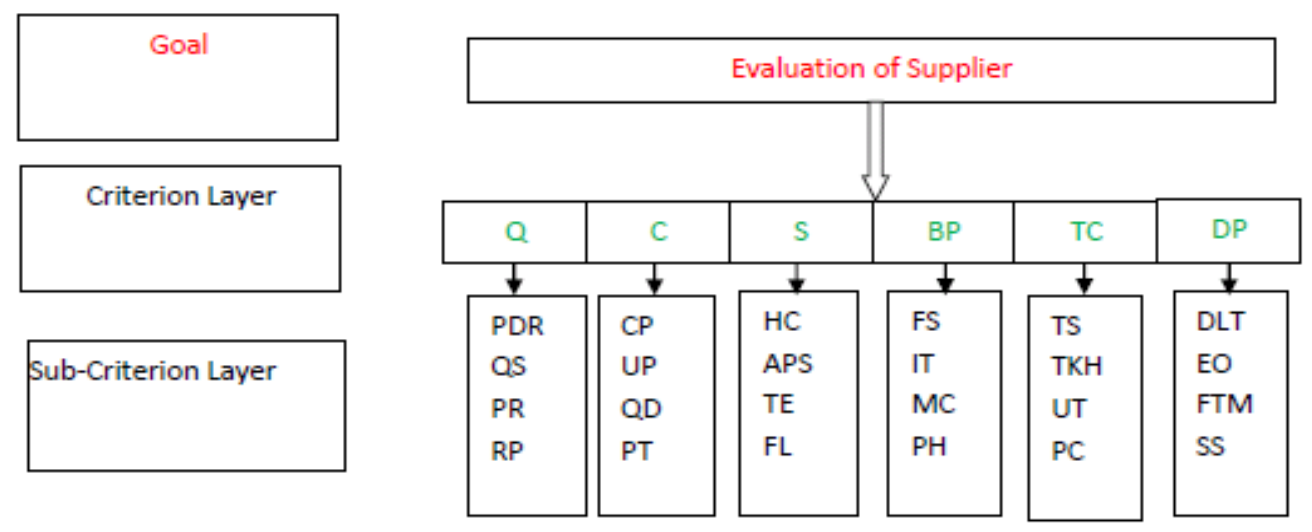

Figure 1: Hierarchy of Evaluation Index System of Supplier performance 
Evaluation of supplier performance is considered as goal. Supplier evaluation criteria namely, Quality (Q), Cost (C), Service (S), Business performance (BP), Technical Capability (TC) and Delivery are considered at criterion level. Sub-criteria under each criterion are given below.

Sub-criteria under Quality (Q): Product durability and Reliability (PDR); Quality systems (QS); Percent Rejection (PR); Reputation and Position in the market (RP);

Sub-criteria under Cost (C): Competitive Pricing (CP); Unit Price (UP); Quantity Discount (QD); Payment Terms (PT);

Sub-criteria under Service (S): Handling of Complaints (HC); Availability of product/service (APS); Training equipment (TE); Flexibility (FL);

Sub-criteria under Business Performance (BP): Financial Stability (FS); IT usage (IT); Management Capability (MC); Personnel Capability (PC);

Sub-criteria under Technical Capability (TC): Technical Support (TS); Technology Know How (TKH); Understanding of Technology (UT); Performance History (PH);

3.6 Sub-criteria under Delivery Performance (DP): Delivery of Lead Time (DLT); Expeditation of Orders (EO); Flexible Transportation Modes (FTM); Safety and Security of Components (SS); Necessary data on the relative importance of criteria/sub-criteria gathered from discussions with the managers of Purchasing, Logistics, Quality Control and Production departments of a pharmaceutical company. These industries need to improve their supply chain performance by concentrating on supplier issues to face with the uncertainty within the business environment.

\subsection{Relative weights of the criteria/sub-criteria}

Relative weights of criteria/sub-criteria are determined as discussed in step 2 of the methodology section. Data is collected by discussion with the managers of Purchasing, Logistics, Quality Control and Production departments to assess the relative importance of the criteria on the supplier performance. Degree of relative importance of criteria is presented with the linguistic variables: Nill-NL;Very Low- VL; Low-L; Medium Low- ML; M- Medium; Medium HighMH; High- H;Very High- VH; Full- F; Aggregated responses of the importance of criteria and sub-criteria in terms of the linguistic variables by the employees of different departments are shown in the table 1.

The study considered the above criteria/sub-criteria from the literature and these are prioritized. Relative weights of criteria and sub-criteria are determined from the aggregated responses shown table 1 and table 2 respectively through Fuzzy Positive Ideal Rating (FPIR) and Fuzzy Negative Ideal Rating (FNIR) approach as discussed in step 2 of the methodology section. Relative weights of criteria and sub-criteria are shown in table 3.From table 3 it is observed that Quality criterion is highly prioritized followed by Technical capability, Delivery Performance, Cost, Service and Business Performance. This is due to the fact that the pharmaceutical company considers Quality is the most important criterion that must be evaluated for successful selection of the supplier. Technical Capability criterion is ranked second since it is an obvious consideration for any pharmaceutical company. Relative weights of the criteria/sub-criteria are shown in fig 2 
Table 1: Aggregated Responses on Criteria

\begin{tabular}{|l|c|c|c|c|}
\hline \multirow{2}{*}{ Criteria } & \multicolumn{4}{c|}{ Departments } \\
\cline { 2 - 5 } & $\begin{array}{c}\text { Purchasin } \\
\text { g (PU) }\end{array}$ & Logistics (LO) & $\begin{array}{c}\text { Quality } \\
\text { Control (QC) }\end{array}$ & $\begin{array}{c}\text { Production } \\
\text { (PR) }\end{array}$ \\
\hline Quality (Q) & E & F & E & E \\
\hline Cost (C) & D & D & E & F \\
\hline Service (S) & D & D & D & E \\
\hline Business performance (BP) & G & G & G & F \\
\hline Technical Capability (TC) & H & H & H & G \\
\hline Delivery Performance (DP) & F & E & F & E \\
\hline
\end{tabular}

Table 2: Aggregated Responses of Sub-criteria

\begin{tabular}{|c|c|c|c|c|c|}
\hline \multirow{2}{*}{ Criteria } & \multirow[b]{2}{*}{ Sub-Criteria } & \multicolumn{4}{|c|}{ Departments } \\
\hline & & PU & LO & $\mathrm{QC}$ & PR \\
\hline \multirow{4}{*}{ Q } & PDR & $\mathrm{H}$ & $\mathrm{H}$ & VH & $\mathrm{VH}$ \\
\hline & QS & $\mathrm{M}$ & $\mathrm{VH}$ & VH & MH \\
\hline & PR & $\mathrm{M}$ & $\mathrm{M}$ & M & M \\
\hline & RP & $\mathrm{MH}$ & $\mathrm{M}$ & M & $\mathrm{MH}$ \\
\hline \multirow{4}{*}{$\mathrm{C}$} & $\mathrm{CP}$ & VH & VH & VH & $\mathrm{H}$ \\
\hline & UP & MH & M & $\mathrm{H}$ & $\mathrm{MH}$ \\
\hline & QD & $\mathrm{H}$ & $\mathrm{MH}$ & $\mathrm{H}$ & $\mathrm{MH}$ \\
\hline & PT & VH & $\mathrm{MH}$ & VH & $\mathrm{H}$ \\
\hline \multirow{4}{*}{$\mathrm{s}$} & $\mathrm{HC}$ & $\mathrm{M}$ & $\mathrm{M}$ & $\mathrm{M}$ & ML \\
\hline & APS & $\mathrm{M}$ & $\mathrm{MH}$ & M & VH \\
\hline & TE & $\mathrm{H}$ & M & M & $\mathrm{M}$ \\
\hline & FL & VH & VH & $\mathrm{H}$ & $\mathrm{MH}$ \\
\hline \multirow{4}{*}{ BP } & FS & $\mathrm{H}$ & VH & VH & $\mathrm{H}$ \\
\hline & IT & MH & $\mathrm{M}$ & M & $\mathrm{MH}$ \\
\hline & $\mathrm{MC}$ & $\mathrm{M}$ & $\mathrm{VH}$ & $\mathrm{H}$ & $\mathrm{M}$ \\
\hline & $\mathrm{PH}$ & $\mathrm{M}$ & $\mathrm{M}$ & \begin{tabular}{|l}
$\mathrm{ML}$ \\
\end{tabular} & ML \\
\hline \multirow{4}{*}{ TC } & TS & $\mathrm{H}$ & $\mathrm{VH}$ & VH & $\mathrm{VH}$ \\
\hline & TKH & $\mathrm{M}$ & VH & VH & $\mathrm{MH}$ \\
\hline & UT & $\mathrm{M}$ & M & M & M \\
\hline & PC & MH & M & M & $\mathrm{MH}$ \\
\hline \multirow{4}{*}{ DP } & DLT & $\mathrm{M}$ & M & M & $\mathrm{M}$ \\
\hline & EO & $\mathrm{H}$ & $\mathrm{VH}$ & VH & $\mathrm{VH}$ \\
\hline & FTM & ML & $\mathrm{M}$ & $\mathrm{M}$ & ML \\
\hline & SS & $\mathrm{H}$ & $\mathrm{VH}$ & M & $\mathrm{VH}$ \\
\hline
\end{tabular}


Table 3: Relative weights of the criteria/sub criteria

\begin{tabular}{|c|c|c|c|c|c|c|c|}
\hline Criteria & Weight & $\begin{array}{l}\text { Sub- } \\
\text { criteria }\end{array}$ & Weight & Criteria & Weight & $\begin{array}{l}\text { Sub- } \\
\text { criteria }\end{array}$ & Weight \\
\hline \multirow[b]{4}{*}{$\mathrm{C}$} & \multirow[b]{4}{*}{0.1542} & $\mathrm{CP}$ & 0.2787 & \multirow[b]{4}{*}{$\mathrm{TC}$} & \multirow[b]{4}{*}{0.2025} & TS & 0.3093 \\
\hline & & UP & 0.214 & & & $\mathrm{TKH}$ & 0.2555 \\
\hline & & QD & 0.2431 & & & UT & 0.2029 \\
\hline & & PT & 0.2642 & & & $\mathrm{PC}$ & 0.2323 \\
\hline \multirow[b]{4}{*}{$\mathrm{S}$} & \multirow[b]{4}{*}{0.1388} & $\mathrm{HC}$ & 0.1941 & \multirow[b]{4}{*}{ Q } & \multirow[b]{4}{*}{0.2219} & PDR & 0.2585 \\
\hline & & APS & 0.3019 & & & $\mathrm{QS}$ & 0.2238 \\
\hline & & $\mathrm{TE}$ & 0.2361 & & & $\mathrm{PR}$ & 0.2053 \\
\hline & & FL & 0.2679 & & & $\mathrm{PC}$ & 0.3124 \\
\hline \multirow[b]{4}{*}{ BP } & \multirow[b]{4}{*}{0.1239} & FS & 0.3148 & \multirow[b]{4}{*}{ DP } & \multirow[b]{4}{*}{0.1587} & DLT & 0.2105 \\
\hline & & IT & 0.2282 & & & EO & 0.3244 \\
\hline & & $\mathrm{MC}$ & 0.2553 & & & FTM & 0.1878 \\
\hline & & $\mathrm{PH}$ & 0.2017 & & & SS & 0.2774 \\
\hline
\end{tabular}

Table 4: Evaluation Responses and Memberships

\begin{tabular}{|c|c|c|c|c|c|c|c|c|c|c|c|}
\hline \multirow{2}{*}{ Criteria } & \multirow{2}{*}{$\begin{array}{c}\text { Sub- } \\
\text { Criteria }\end{array}$} & \multicolumn{5}{|c|}{ Evaluation Responses } & \multicolumn{5}{|c|}{ Evaluation Memberships } \\
\hline & & vs & SA & GE & DS & VD & vs & SA & GE & DS & VD \\
\hline \multirow{4}{*}{ c } & $\mathrm{CP}$ & 13 & 12 & 20 & 19 & 11 & 0.1733 & 0.1600 & 0.2667 & 0.2533 & 0.1467 \\
\hline & UP & 14 & 9 & 32 & 14 & 6 & 0.1867 & 0.1200 & 0.4267 & 0.1867 & 0.0800 \\
\hline & $Q D$ & 11 & 17 & 23 & 14 & 10 & 0.1467 & 0.2267 & 0.3067 & 0.1867 & 0.1333 \\
\hline & PT & 9 & 10 & 30 & 17 & 9 & 0.1200 & 0.1333 & 0.4000 & 0.2267 & 0.1200 \\
\hline \multirow{4}{*}{ s } & $\mathrm{HC}$ & 13 & 17 & 20 & 18 & 7 & 0.1733 & 0.2267 & 0.2667 & 0.2400 & 0.0933 \\
\hline & APS & 13 & 12 & 30 & 9 & 11 & 0.1733 & 0.1600 & 0.4000 & 0.1200 & 0.1467 \\
\hline & TE & 12 & 8 & 32 & 11 & 12 & 0.1600 & 0.1067 & 0.4267 & 0.1467 & 0.1600 \\
\hline & FL & 11 & 15 & 26 & 12 & 11 & 0.1467 & 0.2000 & 0.3467 & 0.1600 & 0.1467 \\
\hline \multirow{4}{*}{ BP } & FS & 13 & 12 & 25 & 16 & 9 & 0.1733 & 0.1600 & 0.3333 & 0.2133 & 0.1200 \\
\hline & IT & 9 & 24 & 23 & 11 & 8 & 0.1200 & 0.3200 & 0.3067 & 0.1467 & 0.1067 \\
\hline & MC & 27 & 14 & 15 & 12 & 7 & 0.3600 & 0.1867 & 0.2000 & 0.1600 & 0.0933 \\
\hline & PH & 24 & 17 & 16 & 6 & 12 & 0.3200 & 0.2267 & 0.2133 & 0.0800 & 0.1600 \\
\hline \multirow{4}{*}{$\mathrm{TC}$} & TS & 23 & 17 & 13 & 12 & 10 & 0.3067 & 0.2267 & 0.1733 & 0.1600 & 0.1333 \\
\hline & $\mathrm{TKH}$ & 20 & 20 & 16 & 12 & 7 & 0.2667 & 0.2667 & 0.2133 & 0.1600 & 0.0933 \\
\hline & UT & 30 & 10 & 15 & 7 & 13 & 0.4000 & 0.1333 & 0.2000 & 0.0933 & 0.1733 \\
\hline & $\mathrm{PC}$ & 21 & 20 & 10 & 18 & 6 & 0.2800 & 0.2667 & 0.1333 & 0.2400 & 0.0800 \\
\hline \multirow{4}{*}{ Q } & PDR & 25 & 17 & 6 & 15 & 12 & 0.3333 & 0.2267 & 0.0800 & 0.2000 & 0.1600 \\
\hline & QS & 18 & 16 & 15 & 13 & 13 & 0.2400 & 0.2133 & 0.2000 & 0.1733 & 0.1733 \\
\hline & $\mathrm{PR}$ & 15 & 10 & 25 & 11 & 14 & 0.2000 & 0.1333 & 0.3333 & 0.1467 & 0.1867 \\
\hline & $\mathrm{PC}$ & 15 & 13 & 28 & 12 & 7 & 0.2000 & 0.1733 & 0.3733 & 0.1600 & 0.0933 \\
\hline \multirow{4}{*}{ DP } & DLT & 21 & 12 & 25 & 10 & 7 & 0.2800 & 0.1600 & 0.3333 & 0.1333 & 0.0933 \\
\hline & $\mathrm{EO}$ & 19 & 7 & 27 & 13 & 9 & 0.2533 & 0.0933 & 0.3600 & 0.1733 & 0.1200 \\
\hline & FTM & 13 & 15 & 22 & 13 & 12 & 0.1733 & 0.2000 & 0.2933 & 0.1733 & 0.1600 \\
\hline & SS & 16 & 9 & 26 & 11 & 13 & 0.2133 & 0.1200 & 0.3467 & 0.1467 & 0.1733 \\
\hline
\end{tabular}




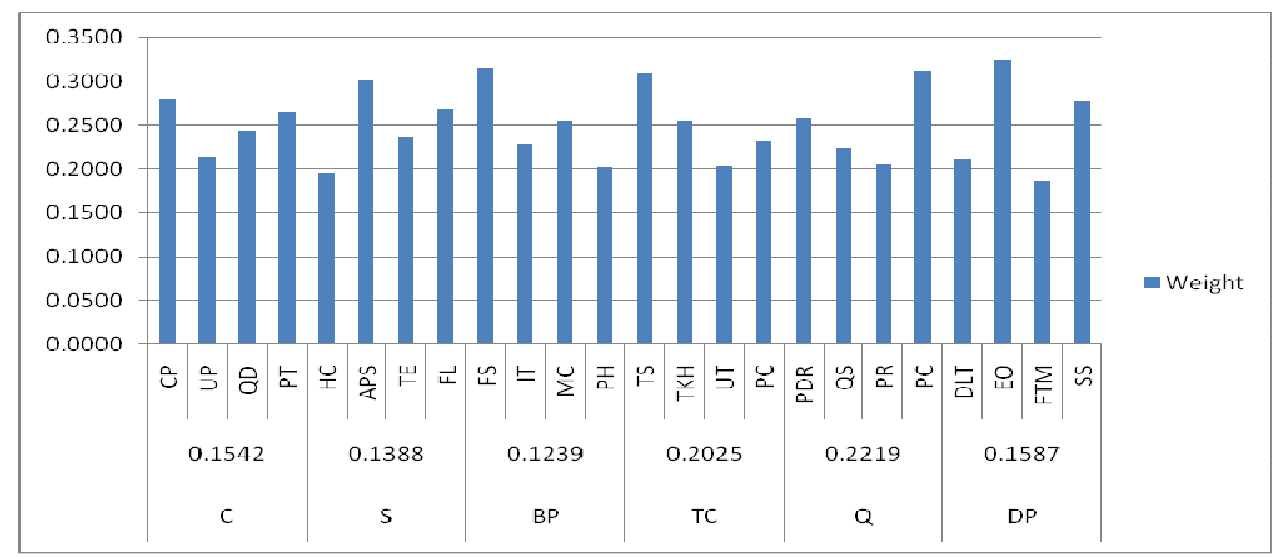

Figure 2: Relative weights of the criteria/sub-criteria

\subsection{Evaluation Membership}

Data on the given supplier performance sub-criteria is obtained from 75 employees of production, Logistics, Quality control and Marketing \& sales departments of the pharmaceutical company. No of employees responded regarding the satisfaction levels in five classes and the membership values are shown in table 4.

\subsection{Evaluation matrix}

Evaluation Matrix is determined as discussed in step 3 of methodology section. Evaluation matrix of supplier's performance is shown below.

$$
\mathrm{U}(\mathrm{S})=\left(\begin{array}{l}
\mu(C) \\
\mu(S) \\
\mu(B P) \\
\mu(T C) \\
\mu(Q) \\
\mu(D P)
\end{array}\right)=\left(\begin{array}{lllll}
0.1530 & 0.1400 & 0.3896 & 0.2093 & 0.1081 \\
0.1632 & 0.1583 & 0.3779 & 0.1576 & 0.1429 \\
0.2365 & 0.2420 & 0.2606 & 0.1422 & 0.1187 \\
0.3324 & 0.2039 & 0.1825 & 0.1503 & 0.1309 \\
0.2581 & 0.1901 & 0.2357 & 0.1751 & 0.1411 \\
0.2458 & 0.1234 & 0.3459 & 0.1566 & 0.1283
\end{array}\right)
$$

\subsection{Final membership Vector}

Final membership vector of the supplier's performance is determined as discussed in step 4 of the methodology section. The Final membership vector of the supplier's performance is shown below.

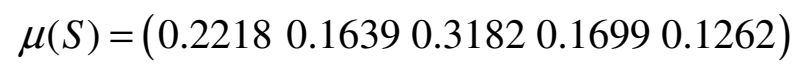




\subsection{Grade of Overall Performance of the supplier}

From the numerical illustration, according to the final membership vector, it is observed that the overall performance of the supplier belongs to the 'General' level with the confidence level of $70.39 \%(22.18 \%+16.39 \%+31.82 \%)$.

\section{RESULTS AND DISCUSSION}

Evaluation membership of supplier's performance is shown in fig 2. From the figure, it is understood that Technical Capability (TC) of the supplier is showing relatively high confidence level of performances of $33.24 \%$ in 'Very Satisfied' level. Cost (C), Service (S), Supplier performance in respect of Business performance (BP), Technical Capability (TC), Quality (Q), and Delivery Performance (DP) are showing confidence levels of 38.96\%, 37.79\%, 26.06\%, $18.25 \%, 23.57 \%$ and $34.59 \%$ respectively in 'General' level.

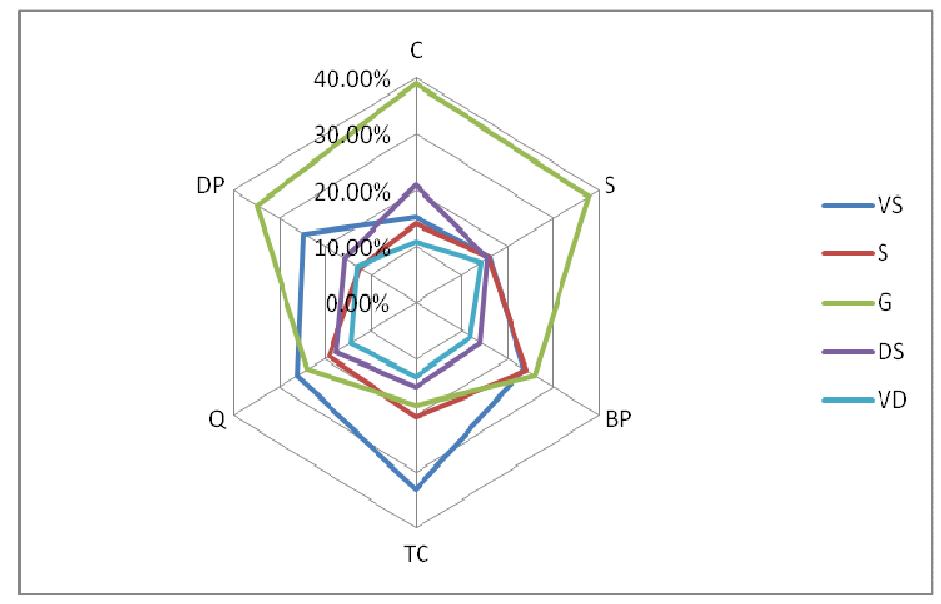

Figure 2: Evaluation memberships of supplier's performance criteria

From the results of the final membership values, it can be judged that the performance of the supplier is considered as 'General' level as the obtained confidence level (70.39\%) is more than the minimum confidence level of $70 \%$. Overall confidence level with 'Very Satisfied' is only $22.18 \%$ indicates that the supplier should improve the performance from every criteria. In the context of supplier evaluation for a pharmaceutical company, the suppliers need to improve quality, technical capability and delivery performance such that the purchasing company will be capable of rapidly responding to changes to their customer demands. Implementing continuous quality improvement methods, making use of latest equipments and machines, implementing new thoughts in business processes will be useful to improve the supplier's performance

\section{CONCLUSIONS}

The proposed methodology is a hybrid methodology that combined the FPIR/FNIR approach with Membership transformation method - M $(1,2,3)$ to evaluate the performance of supplier. The proposed methodology is useful not only to judge the overall performance of the supplier but also to know which criteria/sub-criteria need to be increased. The proposed hybrid method is useful to evaluate the supplier's performance as it is affected by the subjective judgment involved in 
measuring of the criteria/sub-criteria by the stake holders. The methodology maybe extended for the supplier evaluation and selection basing on the supply chain strategy (Lean, Agile and Leagile). To this effect, it requires critical judgment to assess the relative weights among the criteria basing on lean, agile and leagile supply chain strategies. Also, the study can be extended to other areas of decision making in evaluation and ranking of alternatives. Also, the performance of the proposed method can be improved by reducing the subjective judgment in prioritizing the factors/sub-factors.

\section{ACKNOWLEDGEMENTS}

The authors are very much thankful to the reviewer for making constructive comments to improve the quality of the paper.

\section{REFERENCES}

[1] Abbasi.M., R. Hosnavi, and B. Tabrizi, (2013) "An Integrated Structure for Supplier Selection and Configuration of Knowledge-Based Networks Using QFD, ANP and Mixed-Integer Programming Model", Journal of Industrial Engineering, pp.1-8

[2] Amindoust Atefeh, Shamsuddin Ahmeda, Ali Saghafinia and Ardeshir Bahreininejada, (2012) “ Sustainable supplier selection: A ranking model based on fuzzy inference system", Applied Soft Computing, Vol.12, No.6, pp.1668-1677

[3] Boer. Luitzen de, Eva Labro and Pierangela Morlacchi, (2001) " A review of methods supporting supplier selection”, European Journal of Purchasing \& Supply Management, Vol. 7, pp.75-89

[4] Byun. D., (2001) "The AHP Approach for Selecting an Automobile Purchase model", Information and Management, Vol. 38, pp. 289-297.

[5] Chen-Tung Chena, Ching-Torng Linb and Sue-Fn Huang, (2006) "Fuzzy approach for supplier evaluation and selection in supply chain management", International Journal of Production Economics, Vol.102, No.2, pp.289-301

[6] Cheraghi. S. Hossein, Mohammad Dadashzadeh and Muthu Subramanian, (2002) "Critical Success factors For Supplier Selection: An Update", Journal of Applied Business Research, Vol. 20, N0.2, pp.93-108

[7] Dickson, G.W., (1966) "An analysis of vendor selection systems and decisions", Journal of Purchasing, Volume 2, No.1, pp. 5

[8] Deshmukh. Ashish. J and Hari Vasudevan, (2014) "Emerging Supplier Selection Criteria in the Context of Traditional Vs Green Supply Chain Management", International Journal of Managing Value and Supply Chains,Vol.5, No. 1, pp.19-33

[9] Dulmin Riccardo and Valeria Mininno (2003), "Supplier selection using a multi-criteria decision aid method”, Journal of Purchasing and Supply Management Vol. 9, No. 4, pp.177-187

[10] Durga Prasad.K.G , K.Venkata Subbaiah, Ch. Venu Gopala Rao and K.Narayana Rao, (2012) “ Supplier Evaluation Through Data Envelopment Analysis", Journal of Supply Chain Management Systems, Vol.1, No.2, pp.1-11 
[11] Elanchezhian.C., B. Vijaya Ramnath and R. Kesavan, (2010) "Vendor Evaluation Using Multi Criteria Decision Making Technique", International Journal of Computer Applications, Vol. 5, N0.9, pp.4-9

[12] Enyinda, Chris I., Emeka Dunu and Fesseha Gebremikael, (2010) "An Analysis of Strategic Supplier Selection and Evaluation in a Generic Pharmaceutical Firm Supply Chain”, Proceedings of ASBBS, Los Vegas, February 2010, Vol.17, No.1, pp.77-91

[13] Ergün Eraslan and Kumru Didem Atalay, (2014) "A Comparative Holistic Fuzzy Approach for Evaluation of the Chain Performance of Suppliers", Journal of Applied Mathematics, pp.1-9

[14] Eshtehardian Ehsan, Parviz Ghodousi and Azadeh Bejanpour, (2013) "Using ANP and AHP for the Supplier Selection in the Construction and Civil Engineering Companies; Case Study of Iranian Company”, KSCE Journal of Civil Engineering, Vol.17, No.2, pp.262-270

[15] Galankashi Masoud Rahiminezhad, Anoosh Moazzami, Najmeh Madadi, Arousha Haghighian Roudsari and Syed Ahmad Helmi, (2013) "Supplier Selection for Electrical Manufacturing Companies Based on Different Supply Chain Strategies", International Journal of Technology Innovations and Research, pp.1-13

[16] Hua Jiang and Junhu Ruan, (2009) "Fuzzy Evaluation on Network security based on the New Algorithm of Membership Degree Transformation- M(1,2,3)", Journal of Networks, Vol. 4, No.5, pp. 324-331

[17] Jitendra Kumar and Nirjhar Roy, (2010) "A Hybrid Method for Vendor Selection using Neural Network", International Journal of Computer Applications, Vol. 11, No. 2, pp.35-40

[18] Lee. A.H., H.Y.Kans, E-M.Lai, W.M.Way and C.F.Hou, (2007) "TFT-LCD supplier selection by Poun stream manufacture using fuzzy Multi-choice Goal Programming", Proceeding of Computational Intelligence Conference, Banff, Aberta, Canada, pp. 574.

[19] Muralidharan.C, N. Anantharaman., S.G. Deshmukh., (2002) "A multi-criteria group decision making model for supplier rating", The Journal of Supply Chain Management, Vol.38, No.4, pp.22 - 23

[20] Narayana Rao. K., K.Venkata subbaiah, V. Rama Chandra Raju, (2007) "Supplier Selection in Supply Chain Management through Fuzzy Outranking Technique", Industrial Engineering, Vol.XXXVI, No.09, pp.17-21.

[21] Om Pal, Amit Kumar Gupta and R. K. Garg, (2013) "Supplier Selection Criteria and Methods in Supply Chains: A Review", International Journal of Social, Education, Economics and Management Engineering, Vol.7, No.10, pp.1395-1401

[22] Rajkumar Ohdar and Pradip kumar Ray, (2004) "Performance measurement and evaluation of suppliers in supply chain in evalutionary fuzzy based approach", Journal of Manufacturing Technology Management, Vol.15, No.8, pp. $723-734$

[23] Shouhua Yuan, Xiao Liu, Yiliu Tu and Deyi Xue, (2008) "Evaluating Supplier Performance Using DEA and Piecewise Triangular Fuzzy AHP", Journal of Computing and Information Science in Engineering,Vol.8, pp.1-7

[24] Venkata Subbaiah. K., Narayana Rao. K., (2004) "Supplier selection in Supply Chain Management through AHP", Proceedings of VIII Annual International Conference, The Society of Operations Management, Mumbai, pp.72-80 
[25] Yang Jing and Hua Jiang, (2012) "Fuzzy Evaluation on Supply Chains' Overall Performance Based on AHM and M $(1,2,3)$ ", Journal of Software, Vol.7, No.12, pp. 2779-2786

[26] Yucel Atakan and Ali Fuat Guneri, (2011) “ A weighted additive fuzzy programming approach for multi-criteria supplier selection”, Expert Systems with Applications, Vol. 38, pp. 6281-6286

[27] Zadeh, L.A., (1965), "Fuzzy Sets", Information and Control. Vol.8, No.3, pp.199-249. 